\title{
Holocene history of Pacific Water flux through Bering Strait recorded by smectite abundance and $\varepsilon N d$-signature in a southern Chukchi Sea cored sequence
}

TENGFEI SONG ${ }^{1}$, CLAUDE HILLAIRE-MARCEL ${ }^{2}$, ANNE DE VERNAL ${ }^{2}$, YANGUANG LIU ${ }^{3}$ AND RÜDIGER STEIN ${ }^{4}$

${ }^{1}$ Geotop

${ }^{2}$ GEOTOP, Université du Québec à Montréal

${ }^{3}$ First Institute of Oceanography, Ministry of Natural Resources

${ }^{4}$ MARUM - Center for Marine Environmental Sciences and Faculty of Geosciences, University of Bremen

Presenting Author: song.tengfei@courrier.uqam.ca

The low-salinity Pacific Water (PW) entering the Arctic Ocean through Bering Strait (BS) constitutes one third of the freshwater budget of the Arctic Ocean ${ }^{[1]}$, which, in its turn, impacts the Atlantic Meridional Overturning Circulation (AMOC). This PW flux is tightly controlled by the bathymetry of BS ( $\sim 50 \mathrm{~m}$ at Present), thus, through time, by sea-level (SL) changes. In order to document PW flux changes through time, from sedimentary records, we collected five surface samples along a transect from BS to the edge of the Chukchi Sea shelf as a means to calibrate geochemical and mineralogical proxies of Pacific water fluxes. A core from the Chukchi shelf (ARC6-R09, $\left.168.9^{\circ} \mathrm{W}, 72.0^{\circ} \mathrm{N}\right)$ has been used to reconstruct the Holocene history of this gateway. Measurements included $\mathrm{AMS}^{14} \mathrm{C}$, grainsize, XRD-clay minerals, as well as the particulate and exchangeable $\mathrm{Nd}$-isotopes in specific grain-size fractions. So far smectite content and exchangeable $\varepsilon N d$-values decrease northwards and seem the most sensitive proxies of the PW-flux. At the coring site, modern-like sediment properties have been reached progressively, first through a sharp transition from $\sim 10$ to $\sim 4 \mathrm{ka} \mathrm{BP}$, accompanying the deepening of BS with the rising $\mathrm{SL}$, then by a gentler but continuous "neoglacial" trend towards modern values, $\sim 14 \%$ smectite content and exchangeable $\varepsilon \mathrm{Nd}$ value $\sim-3$, thus bearing a very strong Bering Sea signature. This record also suggests that the major impact of the low-salinity PW exported from the Arctic Ocean towards the North Atlantic, thus on the AMOC, was likely achieved at $\sim 5 \mathrm{ka}$ BP when Arctic river discharge was overall stable $\mathrm{e}^{[2]}$. At last, assuming that the first order parameter governing the PW-flux is the bathymetry of the sill, a first order estimation of exchangeable $\varepsilon N d$-value under higher SL conditions, such as those of the Last Interglacial, would indicate a sharp PW-flux increase vs present based on a direct SL-elevation- $\varepsilon N d$ relationship calibrated with Holocene data and the SL rising rate in the last decade.

[1] Woodgate and Aaggard (2005), Geophysical Research Letters 32, L02602.

[2] Wagner, Lohmann, \& Prange (2011), Global and Planetary Change 79, 48-60. 